Stoa

Vol. 10, no. 19, 2019, pp. 40-71

ISSN 2007-1868

\title{
EMOCIÓN Y SENTIMIENTO: ASPECTOS NEUROBIOLÓGICOS DEL PRINCIPIO ÉTICO MATERIAL UNIVERSAL DUSSELIANO
}

\author{
Emotion and Feeling: Neurobiological Aspects of \\ the Dusselian Universal Material Ethical Principle
}

CARLOS I. ONOFRE VILCHIS

Universidad Autónoma de la Ciudad de México

aitet@hotmail.com

RESUMEN: En este artículo se presentan varios argumentos neurobiológicos de las obras de Antonio Damasio. Esto con la finalidad de mostrar que las emociones y los fenómenos que a ellas subyacen son tan esenciales para el mantenimiento de la vida y la maduración posterior del individuo. Los argumentos que sustentan dicha tesis nos otorgan la posibilidad de entender mejor la tesis propuesta por el filósofo, Enrique Dussel Ambrosini, la cual sostiene que —en su forma más elemental— la organización del cerebro humano ha respondido de forma universal al principio ético material universal de producción, reproducción y desarrollo de la vida del sujeto humano. Lo que se busca al exponer algunos razonamientos de Damasio es demostrar que el contenido del principio ético se justifica en lo que Damasio denomina: "el sentir fundamental". Para él, del vínculo insoslayable entre emociones y sentimientos se desprende el mayor logro de la humanidad: "el sentimiento fundamental de la vida".

PAlabras ClaVE: Antonio Damasio - Enrique Dussel · Neurobiología · Ética de la Liberación.

ABSTRACT:In this article several neurobiological arguments of the works of Antonio Damasio are presented. This in order to show that the emotions and phenomena that underlie them are so essential for the maintenance of life and the subsequent maturation of the individual. The arguments supporting this thesis give us the possibility to better understand the thesis proposed by the philosopher, Enrique Dussel Ambrosini, which argues that, in its most basic form, the organization of the human brain has responded universally to the universal ethical material of production, reproduction and 
development of the life of the human subject. What is sought by exposing some of Damasio's reasoning is to demonstrate that the content of the ethical principle is justified in what Damasio calls: "the fundamental feeling". For him, the unavoidable link between emotions and feelings reveals the greatest achievement of humanity: "the fundamental feeling of life".

KEYWORDS: Antonio Damasio · Enrique Dussel · Neurobiology · Ethics of Liberation

\section{Introducción}

Me interesa, por un lado, ampliar la comprensión del §1.1. El sistema cognitivo y afectivo-evaluativo cerebral humano, contenido en la obra dusseliana: Ética de la liberación en la edad de la globalización y la exclusión. Por otro lado, quiero mostrar que el principio ético material universal dusseliano forma parte de la indagación que se hace del sistema afectivo-evolutivo humano de los procesos auto-organizativos de la vida, y aún, autorregulados de la vida social en donde se encuentra contenido el principio material de la ética de la liberación. Pienso enfocarme solamente en la explicación neurológica que nos lleve a saber cómo en estos procesos biológicos, en su forma más elemental de unidades orgánicas, está contenido el principio material de la ética, pues para Dussel, la realidad de la vida humana del sujeto ético-cerebral tiene, en sus sistemas evaluativo-afectivo neuronales, una permanente vigilancia de exigencias y obligaciones, que incorporan internamente los motivos, y que se integra constitutivamente en todas las actividades de los niveles práctico y teórico de toda conducta posible.

Para los fines de mi trabajo, parto de dividir el §1.1., en varias fases argumentativas interconectadas. En la primera, Dussel, apoyándose en Humberto Maturana, busca mostrar los tres grados de "las unidades orgánicas de la vida". En la segunda etapa, Dussel se basa en el Premio Nobel, Gerald Edelman, para probar cómo el sistema nervioso cerebral actúa por selección, a partir de un criterio universal de dar permanencia, reproducción y desarrollo de la vida del sujeto humano. En esta etapa, Dussel se apoya en Edelman para explicar neurobiológicamente la autoconciencia, el tener consciencia de un yo, lo cual es relevante para la reflexión filosófica y más allá de la misma con base en el sistema cerebral evaluativo-afectivo, que ya puede sentir los estímulos o, mejor dicho, ser consciente de ello. En la última fase, Dussel se basa en el neurólogo portugués Antonio Damasio, para sostener que más allá de las sensaciones, las emociones primarias y las secundarias, como la tristeza, la alegría, el temor, el disgusto, etc., está, "el sentir fundamental”, el sentimien- 
to de la vida, que tiene como fin al conjunto de la corporalidad en referencia a la producción, reproducción o desarrollo de la vida del sujeto humano, ese sentiente está intrínseco a la corporalidad.

En este artículo solamente voy a enfocarme en la última fase de la argumentación ${ }^{1}$ porque, desde mi perspectiva, el sentir fundamental de Damasio, contiene de forma natural, en su forma más básica, hasta la más compleja, en su interior, el momento material de la Ética, como la reproducción y desarrollo de la vida, lo cual sería el fundamento universal de una ética como la que propone Dussel. Me parece que la última fase de la argumentación puede usarse como una base para sostener la presencia de la emoción y el sentimiento en la justificación de la obligación de producir y desarrollar la vida humana concreta de cada sujeto ético en comunidad.

Con esta forma de proceder no le estoy restando importancia a las otras etapas de la argumentación, sino que con ello ratifico mi postura de que el estudio contemporáneo de la emoción y el sentimiento, muestra que la mayoría de los seres humanos y no humanos tratan de auto preservarse -en un primer momento - sin conocimiento consciente de ello y sin haber decidido, como entidad individual, emprender nada. Aquí, no voy a plantear el significado común del término emoción, el cual tiende a englobar la idea de sentimiento. Aquí estudiaré ambos conceptos por separado con el objetivo de dar cuenta de la compleja cadena de acontecimientos que empieza con la emoción y termina en el sentimiento. Esta forma de proceder, pienso que es imprescindible para entender — en parte — por qué Dussel cree que la organización del cerebro humano también responde con base en las emociones, los sentimientos y del conjunto de reacciones innatas o automáticas del genoma al principio ético material universal de producción, reproducción y desarrollo de la vida del sujeto humano.

Primeramente se realiza un análisis de la homeostasis, esto con la finalidad de entender que el proceso homeostático — desde las amebas hasta los seres humanos - cuenta con un conjunto de reacciones reguladoras innatas y automatizadas de la gestión de la vida a modo de sistema evaluativo-afectivo. Ello desembocará en el estudio contemporáneo de la emoción y el sentimiento, pues a partir de ambas nociones se puede mostrar que la mayoría de los seres humanos y no humanos tratan de auto preservarse —en un primer momento-

\footnotetext{
${ }^{1}$ Principalmente porque llevar a cabo una reconstrucción de las tres fases o etapas de la argumentación dusseliana es imposible en un texto de esta magnitud, quizás después logre llevar a cabo esta tarea
} 
sin conocimiento consciente de ello y sin haber decidido, como entidad individual, emprender nada. Esta problemática ha adquirido importancia en la filosofía dusseliana al pensar que las emociones y los sentimientos más básicos y sus manifestaciones deben formar parte de la determinación de principios ético materiales de la vida humana. Emoción, sentimiento y regulación biológica juegan entonces un papel importante en el desarrollo de la consciencia humana. Los engranajes más primarios de nuestro organismo intervienen, están implicados, en los procesos más elevados de razonamiento.

Posteriormente se abordan directamente los argumentos neurocientíficos de Antonio Damasio que permiten demostrar que los estados del cuerpo son la esencia del sentimiento, son una forma alterada de pensar que acompaña a la percepción de dicho estado corporal esencial, es el tipo de pensamiento que concuerda, en cuanto al tema, con el tipo de emoción que se siente. Aquí pretendo abordar la problemática de qué constituye un sentimiento. Esto con el afán de robustecer aún más la tesis dusseliana, pues, para Damasio, la noción de emoción y sentimiento no se encuentran separadas, sino entrelazadas en un sentir fundamental: "el sentimiento de la vida". Por último, se vincularán ambas secciones con la finalidad de mostrar la importancia del primer principio ético material universal dusseliano, el cual versa en torno a la producción, reproducción y desarrollo de la vida humana en comunidad. Aquí se abordarán algunas razones que Dussel nos ofrece para afirmar que el sistema cerebral evaluativo-afectivo tiene como criterio la reproducción y el desarrollo de la vida, desde sus niveles más básicos.

Para Dussel, el sistema cerebral es el órgano directamente responsable de la producción, reproducción y desarrollo de la vida, de "el vivir", de forma natural, el cual incluye las emociones y los sentimientos en sus diferentes grados y facetas. Aquí concluyo sosteniendo que todos estos elementos neurológicos desarrollados con el apoyo de Damasio son nuestro punto de partida para entender lo que significa el sistema evaluativo-afectivo como momento constitucional del funcionamiento cerebral. Pues independientemente de que algunas posturas racionalistas ético-actuales no tengan como criterio de verdad, la reproducción y el desarrollo de la vida del sujeto humano, también con emociones y sentimientos. Mínimo ellas requieren empezar sus discursos aceptando el hecho de estar y mantenerse vivas para poder justificarlas. Mi contribución aquí puede considerarse como una defensa del argumento de Damasio y como un intento por ampliar su rango de aplicación. En efecto, pues tal argumento puede usarse como base para sostener las diversas tesis 
dusselianas que afirman el principio ético-universal de la sobrevivencia de los sujetos corporales. El que dicho argumento pueda usarse así no depende solamente de la validez formal del argumento como tal, sino de aceptar que la validez formal no está reñida con la "verdad" de la sobrevivencia de los sujetos, pues la sobrevivencia, como corporalidad viva, incluye a la verdad como su justificación formal.

\section{La emoción como reacción reguladora innata y automatizada de la gestión de la vida en el proceso homeostático}

Enrique Dussel ha desarrollado un pensamiento en el cual se considera que la filosofía moral contemporánea tiene como tarea principal poner en práctica - por lo pronto- seis principios generales: a) El principio de producción, reproducción y desarrollo de la vida humana en comunidad, b) El principio ético-formal de la razón discursiva, c) El principio de factibilidad ética, d) El principio crítico-material, e) El formal intersubjetivo de validez crítica y f) El principio-liberación.

Constituye el tema central de este escrito la crítica que hace nuestro filósofo a las posturas ético filosóficas que no intentan fundamentar una ética material y que tienden a menospreciar y reducir, por lo menos, tres ámbitos: i) las inclinaciones humanas, ii) la vida buena y iii) la negación de la obligación de la supervivencia como principio ético material.

Aquí, toda mi argumentación versará en contra de iii) tomando como base los argumentos esgrimidos por A. Damasio sobre las emociones y los sentimientos, los cuales, a mi parecer, demuestran que la mayoría de los seres vivos, desde las amebas hasta los seres humanos, tratan de preservarse automáticamente y sin conocimiento consciente alguno de lo que llevan a cabo. Es importante enfatizar que la perspectiva en contra de iii), es quizá una de las posturas filosóficas más criticadas, tanto en la filosofía latinoamericana como en la filosofía mundial.

Bien vale la pena, por ello, ocuparse de esta filosofía dusseliana, así como del análisis crítico de sus principales tesis y problemas que siguen siendo vigentes en nuestro continente y más allá del mismo. Dussel se enmarca dentro de lo que sería un diálogo filosófico entre pensadores que practican la ética como discurso. No obstante, Dussel expresa sus diferencias en una selección de textos representativos de la filosofía apeliana y habermasiana. Debemos indicar que, si bien el tema que nos interesa es el de las críticas de Dussel a las formas de pensamiento filosófico que no contribuyen a legitimar el principio 
ético universal de la vida del sujeto humano desde el contenido material de la misma y bajo el aspecto político, económico, ecológico y cultural, que son necesarios para asegurar la continuidad de la vida humana. La problemática central de este artículo será la siguiente: ¿Por qué es necesario mostrar que la vida es un momento esencial del ser humano y no algo de lo que simplemente se vuelve cada uno consciente; para qué legitimar un principio ético-universal que conserve y aumente la vida humana; qué nos está permitido salvaguardar para la reproducción y el crecimiento de la vida; qué papel juega el proceso homeostático en la nueva comprensión de estas dimensiones intrínsecas a la vida humana?

Podemos preguntarnos por la importancia que tiene este análisis sobre los temas que serán abordados. Sin embargo, podemos asegurar que la vida es el primer modo de realidad del ser humano, y que la emoción, el sentimiento y la racionalidad son dimensiones del propio ser viviente, es decir, de la vida humana misma. Son varias las respuestas en juego y nuestra tarea consiste en presentar cómo se realiza la crítica argumentativa a las posturas éticas contemporáneas que no consideran la vida como el momento fundamental y esencial del ser humano.

La tesis de Antonio Damasio sostiene: para que las emociones tengan lugar no hay necesidad de analizar conscientemente el objeto causativo, y mucho menos evaluar la situación en la que aparece. Las emociones pueden operar en marcos distintos.

Lo que busco con la tesis de Damasio es iluminar la maquinaria cerebral de la emoción, la cual, corresponde, por principio, a la naturaleza misma del ser humano como tal. De dicha tesis se puede deducir y explicar por qué Dussel piensa que la organización del cerebro humano responde —en un primer momento- a través de emociones o reacciones innatas a su primer principio ético material universal de producción, reproducción y desarrollo de la vida del sujeto humano. Empiezo con lo siguiente:

En el capítulo 1 de su Ética de la liberación en la edad de la globalización y la exclusión de 1998, Enrique Dussel enfatizaba lo siguiente:

En este capítulo intentaremos indicar algunos elementos, sólo algunos, de un principio universal de toda ética, en especial de las éticas críticas: el principio de la obligación de producir, reproducir y desarrollar la vida humana concreta de cada sujeto ético en comunidad. Este principio tiene pretensión de universalidad. Se realiza a través de las culturas y las motiva por dentro, mismo que a los valores o a las diversas maneras de cumplir la «vida buena», la felicidad, etc. Pero todas estas 
instancias no son nunca el principio universal de la vida humana. El principio las penetra a todas y las mueve a su auto-realización. (Dussel, 1998, p. 91).

En esta sección no pretendo explicar paso a paso el desarrollo argumentativo del primer principio ético material universal dusseliano en su forma positiva. Aquí quiero mostrar que es plausible ampliar la comprensión y demostración de la existencia del principio ético material universal dusseliano de la obligación de producir, reproducir y desarrollar la vida humana concreta de cada sujeto ético en comunidad, a través de las investigaciones neurocientíficas contemporáneas, las cuales demuestran que todos los seres vivos llevan a cabo procesos homeostáticos por medio de los cuales tratan de autopreservarse poniendo en juego las emociones y los sentimientos.

En efecto, Dussel asume la relevancia ética de la vida humana, concretamente, de la corporalidad viviente de cada sujeto. Sin embargo, es necesario situar la noción de corporalidad viviente desde un horizonte más amplio que nos permita comprender qué lo llevo a pensar en ese principio, por qué fundamentar una ética desde la vida humana, qué entiende por vida humana y cómo poder mostrar un panorama completo de la misma en uno o varios principios éticos.

El intento dusseliano de explicar la importancia ética de la vida, viene, desde mi perspectiva, de algunos argumentos de la neurobiología contemporánea que muestran hoy, según Dussel, que la organización del cerebro humano responde universalmente al principio ético material universal de producción, reproducción y desarrollo de la vida del sujeto humano. La tesis parece compleja. Sin embargo, Antonio Damasio, nos muestra, de una manera neurocientífica, que el ser humano es ante todo un ser vivo que ejecuta reacciones reguladoras que dan cuenta de una realidad del ser viviente como tal. Para Damasio, las emociones y los sentimientos son los cimientos de nuestra mente, revelaciones del estado de la vida humana en el seno del organismo entero que hoy conocemos y que denominamos algunas veces como procesos homeostáticos instintivos.

Comencemos con el primer argumento expuesto por Antonio Damasio en la obra En busca de Spinoza, el cual afirma lo siguiente:

Todos los organismos vivos, desde la humilde ameba hasta el ser humano, nacen con dispositivos diseñados para resolver automáticamente, sin que se requiera el razonamiento adecuado, los problemas básicos de la vida. Dichos problemas son: 
encontrar fuentes de energía; mantener un equilibrio químico del interior compatible con el proceso vital; conservar la estructura del organismo mediante la reparación del desgaste natural, y detener los agentes externos de enfermedad y daño físico. La palabra homeostasis es el término apropiado para el conjunto de regulaciones y el estado resultante de vida regulada. (Damasio, 2016, p. 40).

Primero, la homeostasis, podemos imaginarla como un gran árbol multirramificado de fenómenos encargados de la regulación automatizada de la vida. Segundo, ese gran árbol, es resultado de miles de años de evolución, es decir, es un proceso de organización innata y automatizada de la gestión de la vida, desde las reacciones simples a las más complejas. Tercero, que todos los organismos vivos posean mecanismos diseñados para resolver de manera automática los problemas básicos de la vida no implica que todo ser vivo pueda llegar a preservarse, pues se puede nacer con dichos mecanismos, pero, por múltiples factores- quizá no se logren desarrollar de manera adecuada. Con el argumento, tampoco se insinúa que, la vida racional, sea innecesaria, ni mucho menos se aconseja — cuando se es consciente— solamente dejarse llevar por esos dispositivos, como si eso garantizara la permanencia misma de la vida.

Si el argumento anterior es correcto, ello es indicio de un equipamiento innato y automatizado de la gestión de la vida (no solo humana) que poco a poco se volvió refinado. A mi parecer, el argumento intenta decir que la mayoría de los organismos vivos nacen con algunos dispositivos que les permiten luchar a favor de la conservación de su vida. Si la vida como tal permanece o no, es otro asunto, si sigue su curso o no, también. Lo que puede decirse del argumento desde un punto de vista biológico es que "En la base de la organización de la homeostasis, encontramos respuestas simples como el acercamiento o el alejamiento de un organismo entero en relación con algún objeto; o bien aumento de la actividad (excitación) o bien reducción de la misma (calma o quiescencia)." (Damasio, 2016, p. 41).

Es plausible sostener, entonces, que 1) la homeostasis es una manera adecuada de comprender el proceso de organización innato y automatizado de la gestión de la vida. Lo interesante consiste en preguntarse qué sucede con 2): ¿sería suficiente la homeostasis para dar cuenta de la vida en general y de la vida en particular? Creo que la respuesta a esta pregunta no depende de cómo cada uno entiende la vida o la vida humana, sino de pensar críticamente si de 1) es plausible derivar una comprensión más rica y abarcadora de los 
fenómenos encargados de la compleja regulación automatizada de la vida con especies humanas y no humanas.

Pero, ¿qué sucede con 2) cuando 1) se interpreta en sentido reduccionista, bajo el fantasma del determinismo genético? Sucede que la interpretación de 2) no logra convencer a muchos en los términos biológicos mencionados y, de facto, ni siquiera se la toma en consideración. Desde mi perspectiva, este no es el caso de Antonio Damasio, no creo que su planteamiento neurobiológico pueda ser clasificado dentro de las distintas ramas del reduccionismo. Pues, para Damasio: "No basta descubrir las sustancias químicas involucradas en emociones y estados anímicos [...].”(Damasio, 1996, p. 185).

A continuación presentaré otro argumento más ilustrativo de la homeostasis; veamos:

Toda la colección de procesos homeostáticos gobierna la vida momento a momento, en todas y cada una de las células de nuestro cuerpo. Este gobierno se consigue mediante una simple disposición: en primer lugar, algo cambia en el ambiente de un organismo individual, internamente o externamente. En segundo lugar, los cambios tienen la capacidad de alterar el rumbo de la vida del organismo (pueden constituir una amenaza a su integridad, o una oportunidad para su mejora). En tercer lugar, el organismo detecta el cambio y actúa en consecuencia, de una manera designada a crear la situación más benéfica para su propia autopreservación y su funcionamiento eficiente. Todas las reacciones operan según esta disposición y, por ello, son una manera de evaluar las circunstancias internas y externas de un organismo y de actuar en consecuencia. Detectan contratiempos u oportunidades y solventan, mediante la acción, el problema de librarse de los contratiempos o de aprovechar las oportunidades. (Damasio, 2016, p. 46).

Con este argumento, la definición de 1) adquiere mejor comprensión y, por tanto, también 2), por lo cual, 2) puede estar sujeta a la definición de 1). Debe observarse que el hacer depender la respuesta de 2) a la interpretación de 1), a partir de ambos argumentos, solamente tiene por objeto el permitir apreciar con claridad que tales soluciones tienen que hacerse tomando en cuenta el proceso homeostático como punto de arranque; pero, si el proceso homeostático no es considerado como garante de la gestión de la vida, entonces, ha de ser claro que 1) y 2) no pueden recibir dichas interpretaciones directamente y con total independencia de dicho proceso.

Hay algunas cosas dignas de observarse en este argumento. La primera consiste en que todos los procesos homeostáticos gobiernan tanto la vida general como la particular, pues hasta nuestros días no se ha demostrado la au- 
sencia del esfuerzo inexorable de cada ser vivo para preservarse, el proceso homeostático nos muestra la primera realidad de nuestra existencia. Esto no significa que si la vida como tal permanece y sigue su curso, entonces no necesita de ninguna otra instancia, hay que interpretar dicho principio de forma creativa. La vida permanece, pero en relación con otras cosas (descubiertas y por descubrir), con otros organismos, sigue su curso, pero en relación con múltiples factores (internos o externos), como sostiene Damasio, que amenazan o mejoran su integridad. No sólo se trata de mostrar si existe o no una contradicción formal de dicho principio, sino de ampliar el rango de interpretación imaginativa-cognoscitiva que enriquezca nuestra comprensión del por qué la vida busca conservarse, reproducirse y desarrollarse, si ese principio subyace a toda cultura qué es lo que hay en el fondo, quizá no sólo una mera estructura molecular o biomolecular, pero si algún pista —a modo de reacciones reguladoras - por las cuales comenzar, pues como afirma Damasio:

Los niveles inferiores del edificio neural de la razón son los mismos que regulan el procesamiento de las emociones, los sentimientos y las funciones necesarias para la supervivencia del organismo. Esos niveles inferiores mantienen una relación directa y mutua con casi cada órgano del cuerpo, situándolo así directamente en la línea de producción que genera los más altos logros de la razón, de la toma de decisión y, por extensión, de la creatividad y conducta social. Emoción, sentimiento y regulación biológica juegan entonces un papel en la razón humana. Los engranajes más primarios de nuestro organismo intervienen, están implicados, en los procesos más elevados de razonamiento. (Damasio, 1996, p. 13).

La vida es el constante empeño, el inagotable esfuerzo por autopreservarse, en ella prevalece la inagotable actividad. Cada organismo vivo, en la medida de sus posibilidades, se esfuerza para preservarse y perseverar en su ser. Ese empeño constante para preservarse y perseverar en su ser es la esencia real de su ser. La vida de los organismos no se da en bruto, pues hay reacciones básicas y complejas - de por medio que responden a una metódica manera de regulación de sus estructuras y funciones vitales. "[...], cada reacción consiste en reordenamientos chapuceros de pedacitos y partes de los procesos más simples inmediatamente inferiores. Todos están dirigidos al mismo objetivo general, la supervivencia con bienestar, [... ]" (Damasio, 2016, p. 49).

La justificación del proceso homeostático es un ejemplo que tenemos para comprender que a pesar de las circunstancias que ponen en riesgo la vida misma, se sigue luchando por mantenerla. Los organismos nacen con una 
compleja estructura celular que lleva a cabo reacciones que son necesarias para la supervivencia con bienestar. Algunas de estas reacciones han sido asociadas a la emoción desde la regulación homeostática simple.

En efecto, si 1) la homeostasis es una manera adecuada de dar cuenta del proceso de reacciones reguladoras innatas y automatizadas de la gestión de la vida, es necesario admitir que las reacciones reguladoras de la vida a las que nos referimos, responden a un objeto o situación potencialmente peligrosa, o una oportunidad para comer o aparearse. No obstante, como sostiene Damasio, hay otras reacciones que responden a un objeto o situación dentro del organismo.

El siguiente razonamiento nos explica varias cosas:

La gama de reacciones abarca no sólo emociones muy visibles como el miedo o la cólera, sino también instintos, motivaciones y comportamientos asociados al dolor o al placer. Todos ellos tienen lugar en el interior de un organismo, un cuerpo limitado por una frontera, en cuyo interior la vida va marcando el tiempo. Todas las reacciones, de forma directa o indirecta, muestran una clara finalidad: hacer que la economía interna de la vida funcione de manera fluida. La cantidad de determinadas moléculas químicas ha de mantenerse dentro de ciertos márgenes, ni por encima ni por debajo, porque fuera de estos márgenes la vida se halla en peligro. La temperatura debe mantenerse, asimismo, dentro de parámetros estrictos. Hay que procurarse fuentes de energía, y la curiosidad y las estrategias de exploración ayudan a localizar dichas fuentes. Una vez encontradas, estas fuentes de energía han de incorporarse (literalmente en el interior del cuerpo) y modificarse para su consumo o almacenamiento inmediatos; los productos de desecho que resultan de todas las modificaciones han de eliminarse; y la reparación del desgaste de los tejidos ha de realizarse de manera que se mantenga la integridad del organismo.

(Damasio, 2016, p. 50).

He aquí una paráfrasis adecuada del razonamiento de Damasio:

Se nos propone tratar de conocer qué es un ser humano desde la gestación de la vida, por eso, Damasio nos remite a la gama de reacciones (internas y externas) reguladoras innatas y automatizadas de la misma. Algunas de esas reacciones mantienen una conexión insoslayable, pues se comparten el objetivo de la supervivencia y el bienestar. Tanto las reacciones internas como externas se ven obligadas a mantenerse dentro de regímenes, reglas y leyes estrictos que garantizan el adecuado funcionamiento de los organismos. Obviamente pueden existir desajustes inesperados que consiguen poner en riesgo 
el objetivo, pero aun así, los agentes orgánicos buscarán la forma de mantener la integridad del organismo.

De nuevo, al hacer depender —en parte- la respuesta de 2) a la de 1) sólo tiene por objeto ampliar la noción de la vida ( sea particular o general) e indirectamente la noción de ser humano. El proceso homeostático, nos permite conocer cómo una amplia gama de reacciones (internas y externas) reguladoras innatas y automatizadas son capaces de producir, reproducir y desarrollar la vida del ser humano. Algunas de dichas reacciones humanas reciben el nombre de emociones básicas o primarias (repugnancia, miedo, felicidad, tristeza, simpatía y vergüenza), ellas son las encargadas de llevar a cabo una regulación fundamental y necesaria a fin de evitar los peligros o ayudar al organismo a sacar partido de una oportunidad, o indirectamente al facilitar las relaciones sociales.

Por cierto, no estamos afirmando que cada vez que ejecutamos una emoción estemos promoviendo la supervivencia y el desarrollo de la vida. Hay una variada distinción entre las emociones, algunas las empleamos más para fines determinados y otras para objetivos de supervivencia (dependiendo de la circunstancia o el contexto en el que cada organismo se encuentre). "[...] el hecho de que el despliegue de algunas emociones en las circunstancias humanas actuales sea maladaptativo no niega su papel evolutivo en la regulación provechosa de la vida." (Damasio, 2016, p. 51).

Aunque la ira, la tristeza, el miedo o la cólera sean contraproducentes en las sociedades modernas. Aun así, en la historia de la humanidad, ellas contribuyeron de forma positiva a la preservación de la vida, pues gracias a ellas se consiguió salvar miles de vidas. A mi parecer, estas reacciones han podido mantenerse en pie dentro de la cadena evolutiva porque automáticamente apoyaban la supervivencia. Creo que la vida en el reino animal y humano ha estado plagada de estas emociones, por lo que se llega a considerar como irrenunciable la investigación de las mismas. "[... ], comprender la biología de las emociones y el hecho de que el valor de cada emoción difiera tanto en nuestro ambiente humano actual, ofrece considerables oportunidades para entender el comportamiento humano." (Damasio, 2016, p. 51).

El razonamiento que resulta de reflexionar críticamente 1) nos lleva pensar que el proceso homeostático — ligado a las reacciones emocionales_- puede servirnos para dar cuenta de la importancia que tienen las emociones en organismos vivos simples y complejos. He aquí el argumento para el primer tipo de organismo: 
[...], un organismo unicelular sencillo, todo cuerpo, sin cerebro, sin mente, que se aleja nadando de un posible peligro en un determinado sector de su cultivo: quizá una aguja que lo pincha, o demasiadas vibraciones, o demasiado calor, o demasiado poco. $\mathrm{O}$ bien el paramecio puede hallarse nadando rápidamente a lo largo de un gradiente químico de nutrientes hacia el sector del cultivo en el que podrá obtener su pitanza. Este organismo sencillo está diseñado para detectar determinadas señales de peligro (variaciones bruscas de temperatura, vibraciones excesivas o el contacto de un objeto punzante que podría perforar su membrana) y para reaccionar dirigiéndose hacia un lugar más seguro, templado y tranquilo[... ]. Los acontecimientos que estoy describiendo en un organismo sin cerebro ya contienen la esencia del proceso de emoción que poseemos los seres humanos: la detección de la presencia de un objeto o suceso que recomienda evitación y evasión o aprobación y acercamiento. La capacidad de reaccionar de esta manera no ha sido aprendida: no hay mucha pedagogía en la escuela de los paramecios. (Damasio, 2016, p. 52).

Un elemento fundamental de este argumento consiste en proporcionar una defensa directa de la presencia de la esencia del proceso de emoción que compartimos los seres humanos con otros seres vivos (sin cerebro). En efecto, pues si es plausible que dicha esencia exista en tales seres y que ésta posea las reacciones reguladoras innatas y automatizadas, eso significa que la naturaleza proporcionó a los organismos vivos los medios para producir, reproducir y desarrollar su vida — en un primer estadio— de manera automática, sin la necesidad de poner en práctica la consciencia o la racionalidad en un sentido estricto; entonces, en esa medida, también es plausible decir que dicha esencia nos lleva a repensar cierta igualdad de condiciones que son dignas de ser discutidas en los diferentes ámbitos que constituyen la vida en general y particular. Sin embargo, creo que siguen siendo pocos los interesados en sostener que puede hacerse una defensa más sustanciosa de la presencia de las emociones en los susodichos organismos vivos.

Otro aspecto importante del razonamiento anterior radica en aclarar que no se piensa únicamente en los paramecios, desde luego, hay organismos más complejos que poseen un cerebro modesto que les es útil para la supervivencia en ambientes más peligrosos, eso significa que el cerebro es necesario independientemente de que algunos organismos logren sobrevivir sin él, únicamente con las emociones. Para Damasio, "Las moscas tienen emociones, aunque no sugiero que sientan emociones, y mucho menos que reflexionen sobre tales sentimientos." (Damasio, 2016, p. 53). 
Para responder la pregunta de por qué algunos organismos vivos tienen emociones (como las moscas), pero no pueden sentirlas y ni mucho menos llevan a cabo una reflexión sobre los sentimientos. Debemos considerar, según Damasio, que ninguno de dichos organismos produce estas reacciones de forma deliberada, como tampoco van construyendo, parte por parte, las reacciones que les son necesarias para cada caso diferente. Simplemente reaccionan de forma refleja, automática. Esto muestra la distinción, pero no la desvinculación entre una emoción y un sentimiento. De modo que si la emoción expresa un conjunto complejo de respuestas (reacciones), entonces los sentimientos expresan contenidos mentales aún más complejos que vienen precedidos por las emociones.

Las a) emociones de fondo, b) primarias o básicas y c) sociales, son tres de las principales clasificaciones que hoy se emplean para dar cuenta de las mismas. La primera, consiste en que las emociones de fondo no son visibles en nuestro comportamiento, aunque son importantes. Las emociones de fondo son " [... consecuencia del despliegue de determinadas combinaciones de las reacciones reguladoras más sencillas (por ejemplo, procesos homeostáticos básicos, comportamientos de dolor y placer y apetitos), [... ]. Las emociones de fondo son expresiones compuestas de estas acciones reguladoras en la medida en que éstas se desarrollan e intersectan momento a momento en nuestra vida." (Damasio, 2016, p. 55).

La segunda, incluye emociones muy visibles. El miedo, la ira, el asco, la sorpresa, la tristeza y la felicidad. "Dichas emociones son fácilmente identificables en los seres humanos de numerosas culturas, y también en especies no humanas. Las circunstancias que causan las emociones y los patrones de comportamiento que éstas definen son, asimismo, muy constantes en las diferentes culturas y especies." (Damasio, 2016, p. 56).

La última clasificación, c) las emociones sociales, incluyen la simpatía, la turbación, la vergüenza, la culpabilidad, el orgullo, los celos, la envidia, la gratitud, la admiración, la indignación y el desdén. Damasio propone un principio de anidamiento por medio del cual, las tres clasificaciones se ven involucradas en combinaciones diversas, por ejemplo, hay casos en las que c) incorpora respuestas que son parte de las emociones básicas y de las emociones de fondo. "Piénsese de qué manera la emoción social "desdén" toma prestadas las expresiones faciales de "repugnancia", una emoción primaria que evolucionó en asociación con el rechazo automático y beneficioso de alimentos potencialmente tóxicos." (Damasio, 2016, p. 57). 
Aunque las emociones sociales hacen referencia a la sociedad humana y la cultura. Ello no es suficiente para afirmar que dichas emociones están confinadas a los seres humanos, ya que hay animales que exhiben una emoción social sin que se les haya enseñado a realizarlo. Esto sucede porque tal emoción está profundamente arraigada en el cerebro del organismo, dispuesta a ser desplegada cuando la situación apropiada lo amerite. "No hay duda de que la disposición general del cerebro, que permite tales comportamientos complejos en ausencia de lenguaje e instrumentos de cultura, es un don del genoma de determinadas especies." (Damasio, 2016, p. 58).

Dados los prejuicios de superioridad (del ser humano sobre otras especies no humanas) que aún prevalecen en esta época. "Sigue siendo difícil de aceptar, por parte de quien haya sido criado en la convicción de que los comportamientos sociales son los productos necesarios de la educación, de que especies animales simples, no conocidas precisamente por su cultura, puedan exhibir comportamientos sociales inteligentes. Pero lo hacen y, de nuevo, no necesitan mucho cerebro para deslumbrarnos." (Damasio, 2016, p. 62).

Estos patrones de comportamiento social animal son la contraparte de las tan alabadas "posturas racionalistas", las cuales tienden a definir al ser humano esencialmente como ser pensante, principalmente racional. El problema con algunas de estas teorías consiste en que al aplicar sus hipótesis, sus resultados, sí llegan a ser excluyentes ya que no permiten crear un complemento que integre las diferentes influencias de lo innato y de lo adquirido. Sin embargo:

Desde los procesos químicos homeostáticos hasta las emociones propiamente dichas, los fenómenos de regulación vital, sin excepción, tienen que ver, directa o indirectamente, con la integridad y la salud del organismo. Todos estos fenómenos están relacionados por entero con los ajustes adaptativos en el estado del cuerpo, conducentes de modo eventual, a los cambios habidos en la cartografía cerebral de los mismos, que forma la base de los sentimientos. El anidamiento de lo sencillo dentro de lo complejo asegura que la finalidad de regulación siga estando presente en los escalones superiores de la cadena. Aunque la finalidad permanezca constante, la complejidad varía. Las emociones propiamente dichas son ciertamente más complejas que los reflejos; y los estímulos desencadenantes y el objetivo de las respuestas varían asimismo. Las situaciones precisas que inician el proceso y su propósito específico difieren también. (Damasio, 2016, p. 61).

De acuerdo con lo anterior, por ejemplo, el hambre, es un apetito simple, de regulación vital, que sin excepción, tienen que ver, directa o indirectamen- 
te, con la integridad y la salud del organismo. El objeto causativo del hambre comienza siendo interno, pero posteriormente se convierte en externo, pues implica la búsqueda de algo que falta, búsqueda que supone un movimiento exploratorio del entorno natural y una detección sensorial de lo que se busca. No obstante, los objetos causativos de la ira y el miedo, suelen ser casi siempre externos, independientemente de que sean producidos por el recuerdo y la imaginación en nuestro cerebro. De todo lo anterior también se deduce válidamente que:

[...], la mayoría de los animales equipados para sentir emociones por el bien de su vida no posee más dotación cerebral para sentir dichas emociones de la que posee para pensar que tiene dichas emociones, al principio. Detecta la presencia de determinados estímulos en el ambiente y responde a ellos con una emoción. Todo lo que precisa es un aparato de percepción simple: un filtro que detecte el estímulo emocionalmente competente y la capacidad para demostrar emoción. La mayoría de los animales actúa. Probablemente no sienta como nosotros, y mucho menos piense como nosotros. Esto es una conjetura, desde luego, pero está justificada por nuestra idea de lo que se necesita para sentir, [... ]. (Damasio, 2016, p. 62).

Es interesante observar que aunque el sujeto humano es un ser viviente que tiene las estructuras cerebrales necesarias para representar, en forma de mapas sensoriales, las transformaciones que se producen en el cuerpo cuando tienen lugar reacciones emotivas, y ello resulta en la sensación. También la mayoría de los organismos — que carecen de un cerebro preciso- pueden producir reacciones ventajosas que conducen a resultados buenos sin decidir producir tales reacciones, e incluso sin sentir el desarrollo de las mismas. No estoy afirmando que la mayoría de las especies consideren actuar a favor del bien o del mal, tampoco sostengo que sean conscientes de que el adecuado funcionamiento del organismo las lleve a sobrevivir o al bienestar integral. Sin embargo, la presencia del cerebro humano no es suficiente para garantizar a nadie actuar por el bien evitando el mal. "Ni siquiera los seres humanos procuramos la bondad cuando equilibramos el $\mathrm{pH}$ en nuestro medio interno o reaccionamos con felicidad o miedo ante determinados objetos que nos rodean. Nuestros organismos gravitan hacia un "buen" resultado de manera espontánea, a veces directamente como en una respuesta de felicidad, a veces indirectamente como una respuesta de miedo que empieza evitando el "mal" y entonces consigue el "bien". (Damasio, 2016, p. 63). 
El caso hipotético de que la consciencia o la racionalidad sea lo constitutivo del ser humano no es suficiente para demostrar que ella sea la condición absoluta de lo que denominamos la vida humana, pues las emociones no son algo sin importancia, ya que representan el conjunto de reacciones innatas que a través de un largo y complejo proceso evolutivo de las especies han sido y siguen siendo fundamentales para sobrevivir y aumentar el bienestar de la mayoría de los organismos vivos.

El hecho de que las emociones no sean objeto de aprendizaje, que sean automáticas y programas de acción estables y predecibles, revela su origen en el proceso de selección natural y en las instrucciones del genoma resultantes. Estas instrucciones han sido muy bien conservadas a lo largo de la evolución y el resultado se ha ensamblado en el cerebro de una manera tan particular y fiable, que ciertos circuitos neuronales pueden procesar estímulos emocionalmente competentes y hacer que regiones cerebrales que desencadenan emociones construyan una repuesta emocional completa. Las emociones y los fenómenos que a ellas subyacen son tan esenciales para el mantenimiento de la vida y la maduración posterior del individuo, que son desplegadas de manera segura y fiable ya en las fases tempranas del desarrollo individual. (Damasio, 2010, p. 195).

La vida del reino animal y la vida humana ha consistido, en reproducirse, en alimentarse, en luchar y matar para vivir, en protegerse, en preservarse, etc. La vida misma como tal en el nivel orgánico sí tiene importancia porque el ser humano es también una corporalidad sentiente y como tal, no puede entenderse sin su dependencia a la naturaleza. Lo anterior nos lleva a reconsiderar si las emociones que compartimos con la mayoría de las especies merecen o no ser tomadas en cuenta como relevantes hoy en día o si simplemente diremos que son un logro biológico menor.

Hasta aquí mi explicación sobre la homeostasis y el conjunto de reacciones reguladoras innatas y automatizadas de la gestión de la vida. Concluiré esta sección, nuevamente reiterando la defensa de la tesis que forma parte del objetivo esencial de este artículo y que, creo, al vincularla con la tesis de Damasio, pudo ayudarnos a ampliar la comprensión de la tesis dusseliana, la cual afirmaba que la organización del cerebro humano ha respondido de modo universal al principio ético material universal de producción, reproducción y desarrollo de la vida del sujeto humano.

Lo que se buscó con la tesis de Damasio es iluminar la maquinaria cerebral de la emoción, la cual, corresponde, por principio, a la naturaleza intrínseca del ser humano. De dicha tesis se puede deducir y explicar por qué Dus- 
sel piensa que la organización del cerebro humano responde —en un primer momento- a través de emociones o reacciones innatas a su primer principio ético material universal de producción, reproducción y desarrollo de la vida del sujeto humano. Así pues: "Uno de los principales aspectos de la historia del desarrollo humano se refiere al modo en que la mayor parte de los objetos que rodean a nuestro cerebro es capaz de desencadenar una forma $\mathrm{u}$ otra de emoción, débil o fuerte, buena o mala, y puede hacerlo de manera consciente o inconsciente. Algunos de estos disparadores los ha establecido la evolución, pero otros no; por el contrario, nuestro cerebro los ha asociado con objetos emocionalmente competentes en virtud de nuestras experiencias individuales." (Damasio, 2016, p. 66).

\section{El contenido emocional de los sentimientos}

En esta sección pretendo averiguar cuáles son los contenidos mentales de los sentimientos partiendo del intento por comprender la compleja cadena de acontecimientos que empieza con la emoción y termina en el sentimiento. Lo anterior no implica que estemos afirmando que "[...] todos los sentimientos tienen su origen en las emociones" (Damasio, 1996, p. 168). Lo primero que mostraré, como complemento de la sección anterior, es ya una posible definición - a grandes rasgos- de los términos emoción y sentimiento:

[...], las emociones son acciones o movimientos, muchos de ellos públicos, visibles para los demás pues se producen en la cara, en la voz, en conductas específicas. Ciertamente, algunos componentes del proceso de la emoción no se manifiestan a simple vista, pero en la actualidad pueden hacerse "visibles" mediante exámenes científicos tales como ensayos hormonales y patrones de ondas electrofisiológicas. Los sentimientos, en cambio, siempre están escondidos, como ocurre necesariamente con todas las imágenes mentales, invisibles a todos los que no sean su dueño, pues son la propiedad más privada del organismo en cuyo cerebro tienen lugar. (Damasio, 2016, p. 38).

Si lo anterior es correcto, las emociones son un fenómeno que se hace público. Mientras que los sentimientos es la parte que permanece privada. $\mathrm{Si}$ esto es correcto, puede decirse, de nuevo, que el problema de que uno sea público y el otro privado consiste en averiguar si hay uno o varios principios entre la parte del proceso que es pública y la parte que permanece privada. La problemática anterior también radica en saber qué principio(s) gobierna a cada fenómeno y si podemos hablar de un mismo principio cómo influye 
en fenómenos distintos y en escenarios diferentes, pero que quizá no son opuestos. En el contexto de esas problemáticas, deseo entender cuál es el contenido mental, los ingredientes, la materia que constituye un sentimiento. En principio hay al menos una posibilidad provisional al respecto:

Los sentimientos, [...], surgen de cualquier conjunto de reacciones homeostáticas, no sólo de las emociones propiamente dichas. Traducen el estado de vida en curso en el lenguaje de la mente. Propongo que existen "maneras corporales "distintivas que resultan de diferentes reacciones homeostáticas, desde las simples a las complejas. Existen asimismo objetos causativos distintivos, pensamientos consecuentes distintivos y modos de pensamiento consonantes. La tristeza, por ejemplo, está acompañada por tasas bajas de producción de imágenes, a diferencia del rápido cambio de imágenes y del corto intervalo de atención que corresponde a la felicidad suma. Los sentimientos son percepciones, y propongo que el apoyo más necesario para su percepción tiene lugar en los "mapas corporales del cerebro". Dichos mapas se refieren a partes del cuerpo y a estados del cuerpo. Alguna variación del placer o el dolor es un contenido consistente de la percepción que denominamos sentimiento. (Damasio, 2016, p. 100).

Un intento por explicar qué son los sentimientos, de acuerdo con la explicación anterior, es por medio de la percepción de determinados estados del cuerpo junto con la percepción de un cierto modo de pensar y de pensamientos con determinados temas. Para Damasio, los sentimientos surgen cuando la acumulación absoluta de detalles alcanza una fase dada. Aquí no estamos afirmando que los sentimientos sean un mero conjunto de pensamientos con temas concretos, sino que los sentimientos son funcionalmente distintivos debido a que su naturaleza consiste en los pensamientos que representan el cuerpo implicado en un proceso reactivo. "La esencia de un sentimiento puede no ser una elusiva cualidad mental apegada a un objeto, sino más bien una percepción directa en un paisaje específico: el cuerpo." (Damasio, 1996, p. 14).

Me parece que todo lo anterior es fundamental porque si no consideramos con seriedad dicha naturaleza, entonces cómo explicamos la noción de sentimiento al margen de una existente relación entre el cuerpo, el sentimiento y el pensamiento.

Considerar que los sentimientos residen en los diversos pensamientos que representan los estados del cuerpo en un proceso reactivo, nos lleva a preguntar que si alguien no experimenta un determinado estado corporal o mental con cierta similitud a lo que denominamos, por ejemplo, placer, entonces no tiene razón para considerar que su sentimiento sea bueno, positivo. Damasio 
aclara al respecto que: "[... ], el origen de las percepciones que constituyen la esencia del sentimiento es claro: existe un objeto general, el cuerpo, y existen muchas partes de dicho objeto que están siendo cartografiadas continuamente en varias estructuras cerebrales. Los contenidos de dichas percepciones son asimismo claros: diversos estados corporales representados por los mapas que describen el cuerpo a lo largo de toda una gama de posibilidades." (Damasio, 2016, p. 101).

A fin de poder entender correctamente el origen de las percepciones que constituyen la esencia del sentimiento. Considérese el siguiente ejemplo:

[...], es la composición de la sangre en relación con algunas moléculas químicas de las que depende nuestra vida, y cuya concentración está representada, momento a momento, en regiones específicas del cerebro. El estado concreto de aquellos componentes del cuerpo, según estén representados en los mapas corporales del cerebro, es un contenido de las percepciones que constituyen los sentimientos. Los sustratos inmediatos de los sentimientos son las cartografías de innumerables aspectos de estados corporales en las regiones sensoriales diseñadas para recibir señales procedentes del cuerpo. (Damasio, 2016, p. 102).

Para que podamos hablar de la percepción de los sentimientos, es necesario que ocurra el estado concreto de aquellos componentes del cuerpo en relación con representaciones corporales del cerebro. Ello supone que dicha región cerebral está diseñada con sensores para recibir esas señales que provienen del cuerpo. "En el paisaje de tu cuerpo, los objetos son las vísceras (corazón, pulmones, intestinos, músculos), en tanto que luz y sombra, movimientos y sonidos representan un punto en la gama de operación de esos órganos en un momento determinado. Por lo general, un sentimiento es la "vista" momentánea de una parte de ese paisaje corporal." (Damasio, 1996, p. 15).

Debemos tener presente que no registramos de forma consciente la percepción de todos estos estados de partes del cuerpo. Solamente registramos algunos de ellos, de forma muy específica y no siempre agradable. Por ejemplo, no experimentamos que el nivel de glucosa en sangre desciende por debajo de lo mínimo requerido para mantenernos estables — químicamente hablando-, pero sí experimentamos sus consecuencias corporales: fatiga, cansancio, mareo, etc.

Sucede lo mismo cuando experimentamos un específico sentimiento de placer, pues hay que percibir que el cuerpo está de una determinada forma, y percibir el cuerpo de una manera $u$ otra requiere mapas sensoriales en los 
que se ejemplifican patrones neurales y de los que se pueden derivar imágenes mentales. A la pregunta: ¿cuál es el contenido mental, los ingredientes, la materia que constituye un sentimiento? Podemos contestar que el contenido es el mapa de un estado corporal determinado; el sustrato de sentimientos es el conjunto de patrones neurales que cartografía un estado corporal y del que puede surgir una imagen mental del estado en el que se encuentre el cuerpo. En palabras de Damasio: "[...], un sentimiento es una idea; una idea del cuerpo y, de manera todavía más concreta, una idea de un determinado aspecto del cuerpo, su interior, en determinadas circunstancias. Un sentimiento de emoción es una idea del cuerpo cuando es perturbado por el proceso de sentir la emoción.” (Damasio, 2016, p. 103).

Esta definición de los sentimientos es bastante aceptable, pero plantea otro problema; a mi modo de ver, no en la argumentación misma, sino en la probabilidad de si hay algo más en los sentimientos que la percepción del estado del cuerpo.

¿No es tan tajante sólo demostrar que los sentimientos son únicamente la percepción de un determinado estado del cuerpo; qué hay de las ocasiones en las que el sentimiento implica la percepción de un determinado estado corporal y la de un determinado estado mental acompañante? No porque considere que los sentimientos son sólo la percepción de determinados estados del cuerpo dejan de ocurrir interrelaciones entre uno y otros ámbitos.

Según nuestro autor, cuando tenemos imágenes del cuerpo, en paralelo tenemos imágenes de nuestra propia forma de pensar. Son fenómenos que se acompañan mutuamente. Sin embargo, eso no resta complejidad al asunto en juego, pues en determinadas circunstancias de sentimiento, quizá en la variedad más avanzada del fenómeno, el proceso no es en absoluto fácil de interpretar. "En dichas ocasiones, si se toma el ejemplo de un sentimiento positivo, podríamos decir que la mente representa más que el bienestar. La mente representa el mismo bienpensar." (Damasio, 2016, p. 105).

Los estados del cuerpo son la esencia del sentimiento, son una forma alterada de pensar que acompaña a la percepción de dicho estado corporal esencial, es el tipo de pensamiento que concuerda, en cuanto al tema, con el tipo de emoción que se siente. Sentirme triste tiene que ver no sólo con una enfermedad en el cuerpo, sino también con un modo de pensar ineficaz que se encierra alrededor de un número limitado de ideas de pérdida.

En el curso de su argumentación, Damasio también plantea que los sentimientos son percepciones que, en algunos casos, son comparables con otras 
percepciones. Este planteamiento es usado por el autor para mostrar que así como las percepciones visuales reales poseen un objeto en el origen del proceso. Asimismo, los sentimientos tienen su propio centro de origen a partir del cual se desencadenan señales que recorren los amplios mapas del objeto detonador en el interior del cerebro. En el caso de la percepción visual, existe una parte del fenómeno que se debe al objeto, y una parte que se debe a la construcción interna que el cerebro hace de él. Lo que es distinto, en el caso de los sentimientos, los objetos y acontecimientos, es que su origen se halla en el interior del cuerpo y no en su exterior. Esta diferencia establecida causa otras dos:

Primera, además de estar conectados a un objeto en el origen (el propio cuerpo), los sentimientos también lo están al objeto emocionalmente competente que ha iniciado el ciclo de emoción-sentimiento. De una manera curiosa, el objeto emocionalmente competente es responsable de establecer el objeto en el origen del sentimiento. Así, cuando nos referimos al "objeto" de una emoción o de un sentimiento hemos de acotar la referencia y dejar claro qué objeto queremos decir. La visión de un panorama marino espectacular es un objeto emocionalmente competente. El estado corporal que resulta de contemplar dicho paisaje marino $\mathrm{X}$ es el objeto real en el origen X, que después se percibe en el estado de sensación. Segunda, [...], el cerebro tiene un medio directo de responder al objeto a medida que los sentimientos se despliegan, porque el objeto en el origen se encuentra en el interior del cuerpo, tal como se ha dicho. El cerebro puede actuar directamente sobre el objeto mismo que está percibiendo. Puede hacerlo modificando el estado del objeto, o alterando la transmisión de señales desde éste. El objeto en el origen, por un lado, y el mapa cerebral de dicho objeto, por otro, pueden influirse mutuamente en una especie de proceso reverberativo que no se encontrará, por ejemplo, en la percepción de un objeto externo. (Damasio, 2016, p. 106).

Me parece que las dos diferencias desembocan en que es posible sostener que el objeto en el origen, por un lado, y el mapa cerebral de dicho objeto, por otro, pueden intervenir mutuamente en una especie de proceso reverberativo que no se encontrará, por ejemplo, en la percepción de un objeto externo. En la óptica damasiana, los sentimientos " [... ]: requieren de un estímulo emocionalmente competente, dependen de lugares específicos que los desencadenen, [...]".(Damasio, 2010, p.198). Para Damasio, los sentimientos están constituidos por programas de acción eslabonados que hacen intervenir al cuerpo, y son percibidas por el sujeto en forma de emociones o sentimientos. Lo que en este caso se intenta mostrar es que los sentimientos no son una percepción pasiva, sino siempre interactiva entre el cerebro y el cuerpo. Según Damasio, 
después de comenzar un episodio de dichos sentimientos, hay una implicación dinámica del cuerpo, casi con toda seguridad de forma repetida, y una variación dinámica subsiguiente de la percepción. Se desencadena una serie de transiciones a partir de un estímulo emocionalmente competente que involucra al cerebro. Considérese por ejemplo el siguiente estudio realizado:

[...], mi colega David Rudrauf ha investigado el curso temporal de las emociones y sentimientos en el cerebro humano sirviéndose de la técnica de la magnetoencefalografía (MEG). [...]. Al observar el interior del cerebro, Rudrauf siguió el curso temporal de una actividad relacionada con las reacciones emocionales y de los sentimientos a estímulos visuales agradables o desagradables. Desde el momento en que los estímulos fueron procesados en las cortezas visuales, hasta el momento en que los sujetos notificaron por primera vez sentimientos, transcurrieron casi quinientas milésimas de segundo (medio segundo). ¿Poco tiempo? ¿Mucho? Depende de la perspectiva. En términos de "tiempo neuronal" es un intervalo enorme, ya que una neurona puede activarse en unas milésimas de segundo. En términos de "tiempo de una mente consciente", sin embargo, no es mucho, ya que se sitúa entre las doscientas milésimas de segundo que se necesitan para ser conscientes de una pauta al percibirla, y las setecientas u ochocientas milésimas que tardamos en procesar un concepto. (Damasio, 2010, pp. 193-194).

A fin de poder entender correctamente a qué se refiere Damasio con sentimientos de emociones y fenómenos reguladores relacionados, es importante establecer una posible objeción. ¿La disposición emocional que describe Damasio abarca todo tipo de sensaciones?

Según Damasio, el término sensación pertenece al acto de tocar o a su resultado, una percepción táctil. Para él, —respondiendo a la objeción- todos los sentimientos son sensaciones de algunas de las reacciones reguladoras básicas, ya sea, de apetitos, o de emociones, desde el dolor fuerte a la beatitud. "Ya sea a través de designio innato o por aprendizaje, reaccionamos a la mayoría de los objetos, quizá a todos, con emociones, por débiles que sean, y con los sentimientos posteriores, por tenues que sean". (Damasio, 2016, p. 108).

Me parece que de lo anterior todavía podemos preguntar quién puede tener sentimientos independientemente de que, como sostiene Damasio, la mayoría de los seres humanos estemos predispuestos a ello. Examinemos ahora qué requisitos o condiciones son necesarios para sentir. Me parece que son cuatro: a) la presencia de un sistema nervioso; b) la capacidad del sistema nervioso para cartografiar y transformar los patrones neurales en imágenes mentales; 
c) la conciencia y d) la capacidad del cerebro de un organismo para crear los mismos estados corporales que evocan los sentimientos cuando reacciona a objetos y acontecimientos con emociones.

En principio, para que cualquier organismo vivo sea capaz de sentir, es necesario poseer no sólo un cuerpo, sino también una manera de representar dicho cuerpo en su interior. Las plantas, por ejemplo, están vivas pero no pueden representar partes de su cuerpo. En cambio, el cerebro humano sí cuenta con los medios para hacerlo. Según lo anterior, las plantas no contarían con la posibilidad de ser conscientes de un sentimiento. Así pues, el primer requerimiento para sentir es la presencia de un sistema nervioso, cerebral, capaz de representar ciertas partes de su cuerpo.

El segundo requisito nos plantea que el sistema nervioso tiene que poder cartografiar algunas estructuras y estados corporales, para después, transformar los modelos neurales de tales mapas en imágenes mentales. Si el sistema nervioso no fuera capaz de producir imágenes mentales, entonces no podría producirse la idea de lo que regularmente llamamos sentimiento, pues solamente abría una cartografía ajena a la conciencia.

El tercer aspecto para que se produzca un sentimiento implica que el contenido o la imagen mental sean conocidos por parte del organismo. "[...], no podemos sentir si no somos conscientes." (Damasio, 2016, p. 126). La relación entre sentimiento y consciencia no está implicando restarle valor a una u otra. Hay que mirarlas como un proceso complejo del sentir humano que es múltiple, interrelacionado, ramificado y que también contribuye a la creación del yo o de la conciencia. Algunas veces, de la maquinaria de las sensaciones ha dependido eventualmente el desarrollo de la conciencia. En este mismo ámbito, Joseph LeDoux reconoce la importancia de ambos conceptos, en los siguientes términos:

Creo que la experiencia emocional subjetiva, como el sentimiento de tener miedo, surge cuando nos damos cuenta conscientemente de que un mecanismo emocional cerebral como el mecanismo de defensa, está activo. Para que esto suceda, precisamos al menos dos cosas: un mecanismo de defensa y la capacidad de tener el conocimiento consciente de su actividad. (LeDoux, 1999, p. 301).

El último requisito sugiere que el cerebro de un organismo que siente crea idénticos estados corporales que evocan los sentimientos cuando reacciona a objetos y acontecimientos con emociones o apetitos. En organismos capaces 
de sentir, por lo tanto, el cerebro cumple con funciones dobles. Como puede notarse, el cerebro siempre está presente aunque sólo fuera para ordenar o construir el estado corporal emocional determinado que acaba siendo localizado como sentimiento o sensación.

Aunque el cuerpo y el cerebro son fundamentales para que ocurran los sentimientos. Los últimos también dependen de "[...] la existencia previa de la maquinaria cerebral de regulación vital, la cual incluye la parte del mecanismo regulador de la vida causante de reacciones como las emociones y los apetitos." (Damasio, 2016, p. 127). Esto significa que sin la existencia previa de tal maquinaria cerebral capaz de representaciones corporales no hubiera podido ser posible hablar de sentimientos y emociones. Ahora se puede decir que sin cuerpo, sin cerebro y sin maquinaria cerebral que actúa según el principio de regulación de la vida no hubiera sido posible el desarrollo evolutivo de la conciencia humana. Así pues, todo parece estar interconectado de alguna forma.

\section{Vinculación y relevancia de algunos aspectos del primer principio ético material universal dusseliano}

A lo largo de este artículo hemos analizado algunos argumentos neurobiológicos de A. Damasio sobre las categorías de emoción y sentimiento, los cuales consideramos relevantes para comprender —en parte- la importancia del primer principio ético material universal dusseliano, el cual versa en torno a la producción, reproducción y desarrollo de la vida humana en comunidad. Sólo hemos abordado algunos aspectos fundamentales de su pensamiento neurocientífico de forma somera y a modo de presentación de conceptos y argumentos. Ahora pasamos a vincularlos con algunas razones que Dussel nos ofrece para afirmar que el sistema cerebral evaluativo-afectivo tiene como criterio la reproducción y el desarrollo de la vida, desde sus niveles más básicos. En esta sección iré trazando un nexo comparativo entre ambos pensadores que sirva como fundamentación neurológica del principio de la producción, reproducción y desarrollo de la vida humana. También pienso señalar que el sistema cerebral es el órgano directamente responsable de "el vivir", de forma natural, el cual incluye las emociones y los sentimientos en sus diferentes grados y facetas. Aquí concluyo sosteniendo que todos estos elementos neurológicos desarrollados con el apoyo de Damasio son nuestro punto de partida para el tratamiento de algunas críticas realizadas al proyecto de una ética de la liberación latinoamericana. 
Dije al principio de mi exposición que Dussel en el capítulo 1 de su Ética de la liberación en la edad de la globalización y la exclusión de 1998, enfatizaba lo siguiente: "En este capítulo intentaremos indicar algunos elementos, [...], de un principio universal de toda ética, en especial de las éticas críticas: el principio de la obligación de producir, reproducir y desarrollar la vida humana concreta de cada sujeto ético en comunidad." (Dussel, 1998, p. 91).

Para Enrique Dussel, justificar dicho principio ético significó -en primera instancia- desarrollar varios aspectos: $§ 1.1$. El sistema cognitivo y afectivoevaluativo cerebral humano, §1.2. El utilitarismo, §1.3. El comunitarismo, $\S 1.4$. Algunas éticas de contenido o materiales y el $\$ 1.5$. El criterio y el principio material universal de la ética. Como di a conocer al inicio de mi escrito, solamente me ocupo del §1.1., el cual, lo dividí en tres fases argumentativas que se encuentran involucradas.

En la primera, Dussel, apoyándose en Humberto Maturana, busca mostrar los tres grados de "las unidades orgánicas de la vida". En la segunda etapa, Dussel se basa en el Premio Nobel, Gerald Edelman, para probar cómo el sistema nervioso cerebral actúa por selección, a partir de un criterio universal de dar permanencia, reproducción y desarrollo de la vida del sujeto humano. En esta etapa, Dussel se apoya en Edelman para explicar neuro-biológicamente la autoconciencia, el tener consciencia de un yo, lo cual es relevante para la reflexión filosófica y más allá de la misma con base en el sistema cerebral evaluativo-afectivo, que ya puede sentir los estímulos o, mejor dicho, ser consciente de ello.

En la última fase, Dussel se basa en el neurólogo portugués Antonio Damasio, para sostener que más allá de las emociones secundarias, como la tristeza, la alegría, el temor, el disgusto, etc., está, "el sentir fundamental", el sentimiento de la vida, que tiene como fin al conjunto de la corporalidad en referencia a la producción, reproducción o desarrollo de la vida del sujeto humano, ese sentiente está intrínseco a la corporalidad. Me parece que la última fase de la argumentación puede usarse como una base para sostener la presencia de la emoción y el sentimiento en la justificación de la obligación de producir, reproducir y desarrollar la vida humana concreta de cada sujeto ético.

Una de las principales afirmaciones dusselianas aducidas a favor de la presencia del sistema nervioso es la siguiente:

[...], de la misma manera que el sistema inmunológico o el proceso evolutivo de las especies, el sistema nervioso cerebral actúa por selección, a partir de un 
criterio universal de dar permanencia, reproducir, desarrollar, hacer crecer la vida del sujeto humano, y esto desde el nivel vegetativo hasta el cultural o ético más heroico o sublime. (Dussel, 1998, p. 94).

Según Dussel, estos procesos o sistemas que actúan por selección persiguen un mismo objetivo: producir, reproducir y desarrollar la vida. Lo anterior no contrasta demasiado con las afirmaciones de Damasio, pues, según el neurólogo portugués:

[...], cada parte elemental de nuestro organismo, cada célula del cuerpo no sólo está animada, sino que está viva. Más todavía: cada célula es un organismo vivo individual con una fecha de nacimiento, ciclo biológico y fecha de muerte probable. Cada célula es un ser que debe ocuparse de su propia vida y ésta depende de las instrucciones de su propio genoma y de las circunstancias de su ambiente. Los dispositivos innatos de regulación vital [...] en relación con los seres humanos, están presentes a lo largo de toda la escala biológica en todos y cada uno de los sistemas de nuestro organismo, en cada órgano, tejido, célula. (Damasio, 2016, p. 146).

De acuerdo con Dussel y Damasio, todo sistema basado en la selección actúa con referencia al valor. Bajo este supuesto se puede pensar en la existencia de varios mecanismos de regulación biológica que responden al primer principio de la ética dusseliana; veamos el siguiente ejemplo:

Los niveles inferiores del edificio neural de la razón son los mismos que regulan el procesamiento de las emociones, los sentimientos y las funciones necesarias para la supervivencia del organismo. Esos niveles inferiores mantienen una relación directa y mutua con casi cada órgano del cuerpo, situándolo así directamente en la línea de producción que genera los más altos logros de la razón, de la toma de decisión y, por extensión, de la creatividad y conducta social. Emoción, sentimiento y regulación biológica juegan entonces un papel en la razón humana. Los engranajes más primarios de nuestro organismo intervienen, están implicados, en los procesos más elevados de razonamiento. (Damasio, 1996, p.13).

De nuevo, emoción, sentimiento, razón y regulación biológica juegan entonces un papel fundamental en el desarrollo de los diferentes mecanismos de regulación biológica. A pesar de que Charles Darwin demostró la esencia de estos descubrimientos cuando escribió acerca del origen de las especies, sigue resultando curioso hoy en día que "[...], cuando el hombre y otros animales 
son vistos como creaciones separadas, se levanta una barrera frente a nuestro deseo natural de investigar hasta donde sea posible las causas de la [...]" (Darwin, 1984, p. 43) supervivencia de dichas especies.

Es relevante notar que el sistema afectivo-evaluativo constituye un momento del proceso de categorización, de la misma manera la categorización conceptual reorganiza el sistema de valores ordenándolos, por su parte, también en base al criterio de la reproducción y el desarrollo de la vida del sujeto orgánico humano. Examinemos lo que propone Dussel:

[...], la "conciencia primaria" de algo [...] se alcanza, al menos, por el grado de evolución de los mamíferos superiores que cuentan con un sistema límbico y con una memoria conceptual suficiente, y con una conexión neuronal que comunica el córtex con el tálamo, permitiendo el "retorno (reentry)" de las señales desde "la memoria con categorías de valores y los mapeos globales encargadas de la categorización perceptual en el tiempo real". "Tener-conciencia" de que esto es un "alimento" (o un "veneno") supone poder captar la diferencia del "sí mismo (Self)" (todavía no de un "yo") y de lo "no-sí-mismo" (nonself)" y el tener la capacidad para confrontar lo que enfrenta al organismo con la memoria de eso mismo recordado [...]. (Dussel, 1998, p. 97).

Me parece que de las citas anteriores se desprende que es posible aceptar que en el fondo de las explicaciones neurobiológicas se encuentra el sistema cerebral evaluativo-afectivo. Además, prima facie es fenomenológicamente constatable la existencia de dicho sistema en la mayoría de las especies mediante la mera observación empírica; su explicación teórica, científica o filosófica es otro asunto. En principio hay que aceptar que la mayoría de las especies animales e incluso los seres humanos tienen

[...], sensores nerviosos que transportan la información necesaria al cerebro, los núcleos nerviosos y las vainas de los nervios que cartografían la información en su interior son células vivas, sujetas a los mismos peligros para la vida que tienen las demás células, y necesitadas de una regulación homeostática comparable. Estas neuronas no son observadores imparciales. No son vehículos inocentes o pizarras borradas o espejos a la espera de que algo se refleje en ellos. (Damasio, 2016, p. 146).

Es importante no olvidar que Dussel busca fundamentar la validez ética de la producción, reproducción y desarrollo de la vida del sujeto humano. En principio, apoyándose de varias investigaciones neurobiológicas, pero, sobre todo, en las que realizó Damasio. Emoción, sentimiento, estado corporal 
emocional, cerebro, regulación homeostática, etc., son algunos de los principales conceptos que le permiten plantear una fundamentación ética de dicho criterio. Recurriendo a la relevancia contemporánea que tienen los supuestos neurológicos es posible, para Dussel, admitir que más allá de las emociones de fondo, primarias o secundarias, hay un sentir fundamental aún más radical.

En "El error de Descartes", Damasio argumenta a favor de un sentimiento fundamental que se origina en un estado corporal fundamental más que en estados emocionales. Dicho sentimiento, es el sentimiento de la vida misma, un sentimiento base que corresponde al estado corporal prevaleciente entre las diferentes emociones.

He aquí, lo que Damasio sostiene:

Lo llamo sentimiento de fondo porque se origina en estados corporales "de fondo"i y no en estados emocionales. No hablamos aquí del Verdi de la gran emoción, no del Stravinsky de la emoción intelectualizada, sino más bien de un minimalista en tono y ritmo, del sentimiento de la vida misma, del sentido de ser. [...], los sentimientos de fondo no son ni demasiado positivos ni demasiado negativos, si bien se los puede percibir como sobre todo placenteros o displacenteros. [... ]. Un sentimiento de fondo no es lo que sentimos cuando brincamos de alegría ni cuando estamos abatidos por un amor perdido; esos son estados corporales emocionales. El sentimiento de fondo corresponde, en cambio, al estado corporal que predomina entre emociones. [...]. El sentimiento de fondo es nuestra imagen del paisaje corporal cuando no está sacudido por la emoción. (Damasio, 1996, p. 175).

Esta explicación es fundamental, pero requiere una interpretación; a mi modo de ver, el sentimiento de fondo es un estado corporal que predomina entre las emociones. Es la capacidad de algunos seres humanos para actualizar constantemente la representación de su cuerpo, ello permite reconocer, mediante el sistema somatosensorial, automática y prontamente que la realidad de su paisaje corporal va cambiando. Lo anterior, implica distinguir entre el "estado de ánimo" y el "sentimiento de fondo". Cuando, por ejemplo, sientes alegría o tristeza, el sentimiento de fondo es nuestra imagen del paisaje corporal cuando no está sacudido por la emoción. En cambio, el estado de ánimo, a pesar de vincularse con el sentimiento de fondo, no lo captura exactamente. "El estado corporal de fondo está sujeto a continuo seguimiento, y así es interesante preguntarse qué sucedería si de súbito desapareciera; si, cuando te preguntan cómo te sientes, descubrieras que ignoras tu sensación corporal; [...].”(Damasio, 1996, p. 178). 
Vemos, pues, como sostiene Dussel que: "Cuando se nos pregunta: ¿Cómo te encuentras? ¿Cómo te sientes?, respondemos con un general: ¡Muy bien! ¿A qué corresponde exactamente lo que decimos que "nos encontramos" o "sentimos" muy bien? Se trata de un sentir general reflejo acerca de la corporalidad como totalidad, [... ].”(Dussel, 1998:101). Así pues, conviene indagar cuáles son los elementos que constituyen en su totalidad ese estado general de satisfacción ( sentimiento fundamental) al que Dussel se refiere cuando respondemos las preguntas: ¿Cómo te encuentras? ¿Cómo te sientes? ¿De verdad será posible plantearnos una distinción entre la alegría o gozo y la sensación de placer? En relación con esta última cuestión, cito a Dussel:

Todo esto está relacionado al fin conjunto de la corporalidad en sus diversos niveles, en referencia a la permanencia, reproducción o desarrollo de la vida del sujeto humano. Si a esto agregáramos las "evaluaciones" culturales ( las de un egipcio diversas a las de un griego, de un azteca, a las de un español o moderno europeo, etc.) tendríamos un nuevo "sentir evaluativo general reflejo" ( la conciencia moral o ética), que "monitorea" ( subsume) toda la existencia no sólo en el nivel visceral de la corporalidad, sino en el nivel cultural-histórico de la misma corporalidad en un estado autoconsciente y lingüístico como actor social de los valores culturales ( incorporado cerebralmente en las áreas más desarrolladas y recientes de los lóbulos corticales lingüísticos, perfectamente articulados con el sistema límbico y base del cerebro, produciendo una unidad compleja de los diversos órdenes evaluativoafectivos).(Dussel, 1998, p. 102).

Importa observar que tanto Dussel como Damasio relacionan de manera muy interesante las funciones del sistema evaluativo-afectivo cerebral con el sistema de categorización conceptual (teórico-práctico). La posible respuesta a la pregunta: ¿Cómo te encuentras? ¿Cómo te sientes?, abarca ya un sinfín de elementos que conforman y confirman la corporalidad en sus diversos niveles, los cuales, están haciendo referencia a la permanencia, reproducción o desarrollo de la vida del sujeto humano integral.

Finalizaré este artículo comentando algunas coincidencias de Dussel y Damasio, relativo tanto a las emociones, los sentimientos y las funciones cerebrales, a la luz del principio de la obligación de producir, reproducir y desarrollar la vida humana concreta de cada sujeto ético en comunidad.

Con base en lo expuesto, el comentario que puede hacerse sobre estas "coincidencias" es más importante de lo que parece. Esto por el hecho de que la solución a las distintas problemáticas sociales actuales debe ser distinta a las tradicionales. La Ética de la Liberación es una de esas posibles respuestas 
distintas, ya que se sitúa entre las éticas contemporáneas que defienden la autonomía, la libertad y la responsabilidad del sujeto ético-cultural e histórico.

Pues bien, resultó interesante observar cómo Damasio demuestra que las emociones y los sentimientos pueden ser los sensores mentales del interior del organismo, testimonios de la vida en marcha. Ambos son manifestaciones mentales de equilibrio y armonía, de disonancia y discordancia. Con las emociones y los sentimientos - a modo de proceso homeostático- no solo se busca la supervivencia, sino la supervivencia con bienestar. He aquí una coincidencia con el objetivo de la Ética de la Liberación. Dussel, haciendo referencia a la neurobiología actual, afirma que "[...], la evolución produce las condiciones cerebrales para que pueda darse la posibilidad de fundamentar dialéctica y materialmente el fenómeno ético (que se establece en el nivel de las funciones "mentales superiores" del cerebro, en procesos lingüísticos y culturales [...]". (Dussel, 1998, p. 104).

Con Damasio se nos muestra que la mayoría de los organismos vivientes y sus estructuras permanecen mientras se mantiene la vida. He aquí otra coincidencia con Dussel, pues sin producción, reproducción y desarrollo de la vida son imposibles las emociones y los sentimientos como tal. Por tal razón, Dussel recurre a Maturana, Edelman, Damasio, etc., para demostrar que la mayoría de las especies tiene, en sus sistemas evaluativo-afectivo neuronales, una permanente vigilancia de exigencias, obligaciones, un "deber ser" que incorpora internamente los motivos, y que se integra constitutivamente en todas las actividades propias de la existencia misma.

\section{Bibliografía}

Apel, K. O. y E. Dussel, 2005, Ética del discurso; ética de la liberación, Trotta, Madrid.

Brailowsky, S., D. G. Stein/B. Will, 1992 El cerebro averiado. Plasticidad cerebral y recuperación funcional, Fondo de Cultura Económica, México.

Damasio, A., 1966, El error de Descartes. La razón de las emociones, Editorial Andrés Bello, Chile.

—, 2010, Y el cerebro creó al hombre. ¿Cómo pudo el cerebro generar emociones, sentimiento, ideas y el yo?, Ediciones Destino, Barcelona.

—, 2016, En busca de Spinoza. Neurobiología de la emoción y los sentimientos, Paidós, México.

Darwin, Ch.,1984, La expresión de las emociones en los animales y en el hombre, Alianza, Madrid.

Dennet, D., 1991, La conciencia explicada. Una teoría interdisciplinar, Paidós, Barcelona. 
Dussel, E., 1998, Ética de la liberación en la edad de la globalización y la exclusión, Trotta, Madrid.

, 2011, Filosofía de la liberación, Fondo de Cultura Económica, México.

—, 2015, Filosofías del Sur. Descolonización y Transmodernidad, Akal, México.

Elster, J., 2002, Alquimias de la mente. La racionalidad y las emociones, Paidós, Barcelona.

Goldberg, E., 2002, El cerebro ejecutivo. Lóbulos frontales y mente civilizada, Crítica, Barcelona.

LeDoux, J., 1999, El cerebro emocional, Editorial Planeta, Barcelona.

Smith, P., 2012, El cerebro moral. Lo que la neurociencia nos cuenta sobre la moralidad, Paidós, Barcelona.

Recibido el 12 de febrero de 2018

Aceptado el 8 de marzo del 2018 